Canadian Science Publishing

Canadian Journal of Physiology and Pharmacology Revue canadienne de physiologie et pharmacologie

\title{
Bisphenol A interferes with swine vascular endothelial cell functions
}

\begin{tabular}{|r|l|}
\hline Journal: & Canadian Journal of Physiology and Pharmacology \\
\hline Manuscript ID & cjpp-2016-0180.R3 \\
\hline Manuscript Type: & Article \\
\hline Complete List of Authors: & $\begin{array}{l}\text { Basini, Giuseppina; Universita degli Studi di Parma Dipartimento di Scienze } \\
\text { Medico-Veterinarie } \\
\text { Bussolati, Simona; Universita degli Studi di Parma Dipartimento di Scienze } \\
\text { Medico-Veterinarie } \\
\text { Grolli, Stefano; Universita degli Studi di Parma Dipartimento di Scienze } \\
\text { Medico-Veterinarie } \\
\text { Ramoni, Roberto; Universita degli Studi di Parma Dipartimento di Scienze } \\
\text { Medico-Veterinarie } \\
\text { Grasselli, Francesca; Universita degli Studi di Parma Dipartimento di } \\
\text { Scienze Medico-Veterinarie }\end{array}$ \\
\hline Keyword: & AOC; angiogenesis; VEGF; NO \\
\hline &
\end{tabular}




\section{Bisphenol A interferes with swine vascular endothelial cell functions}

2 Giuseppina Basini, Simona Bussolati, Stefano Grolli, Roberto Ramoni, Francesca

3 Grasselli

4 Abstract. Several studies demonstrate that the endocrine distuptor Bisphenol A 5 (BPA) negatively affects animal and human health. Angiogenic process has been 6 suggested among the events disrupted by this molecule, but the underlying 


\section{Introduction}

The heterogeneous family of endocrine disruptors includes the organic compound of industrial origin 2,2-bis (4-hydroxyphenyl)propane $\left(\mathrm{C}_{15} \mathrm{H}_{16} \mathrm{O}_{2}-\mathrm{MW}\right.$ 228.0 Da), known as bisphenol A (BPA), that can be either polymerized to produce polycarbonates, epoxy resins, or employed as a precursor in special flame retardants (Welshons et al. 2006).

As a consequence, BPA can be found in a wide variety of consumer goods such as cutlery, polycarbonate bottles, linings of food cans, dental sealants, thermal fax paper, compact disks, car parts, adhesives, coatings of electrical and electronic parts. In addition, due to its inhibitory action on polymerization and antioxidant effect BPA is used in the production of PVC (Lyons 2000). The population is therefore constantly subjected to significant exposure to BPA released from these materials in consequence of exposure to physical (heat) and/or chemical agents such as acid or basic compounds (Welshons et al. 2006). In humans, contaminating BPA has been detected in follicular fluid, fetal and maternal serum, amniotic fluid (Ikezuki et al. 2002), breast milk (Kuruto-Niwa et al. 2007), placental tissues (Schonfelder et al. 2005), saliva (Olea et al. 2007) and urine (Calafat et al. 2005). Being lipophilic, BPA can accumulate in adipose tissue: significant levels were detected in half of the breast adipose tissue samples examined by Fernandez and colleagues (Fernandez et al. 2007). In addition, the data showing a widely spread environmental distribution of BPA have stimulated scientists to verify potential health risks deriving from exposure to the substance. In male rodents, perinatal exposure to BPA has been associated with a variety of effects on the reproductive system, such as a decrease of sperm production, the disruption of prostate development (vom Saal et al. 1998) and increased susceptibility to prostate carcinogenesis (Ho et al. 2006). As for the female (Caserta et al. 2014), BPA disrupts mammary gland function (Markey et al. 2001) and normal estrous ciclicity (Rubin et al. 2001), impairs steroidogenesis (Grasselli et al. 2010) and ovarian morphology (Markey et al. 2003), and causes precocious puberty (Howdeshell et al. 1999). Moreover, the activity of the endocrine disruptor BPA extends beyond its ability to mimic, promote or inhibit the activity of endogenous 
estrogens and and/or interfere with the action of nuclear hormone receptors, since it also includes effects on thyroid function (Moriyama et al. 2002) on the immune system (Alizadeh et al. 2006) as well as on the development, differentiation and function of the central nervous system (Miyatake et al. 2006; Rubin et al. 2006). BPA also exerts its actions by means of cell-and tissue-specific mechanisms, still uncompletely understood, that modulate a wide range of intracellular signaling pathways (Wetherill et al. 2007).

In 2001, Long et al. have demonstrated, for the first time, a potential modulatory action of BPA on the angiogenic process, documenting in particular its stimulatory effects on the expression of VEGF mRNA in the rat uterus, vagina and pituitary. Moreover, a study on murine endothelial cells has revealed the ability of BPA to induce the synthesis of nitric oxide (Noguchi et al. 2002). Buteau-Lozano and colleagues (2008) have demonstrated an increase of VEGF production in breast cancer cells treated with BPA, that is carried out by means of an ERs-dependent mechanism. In contrast to these findings, a recent paper (Bosquiazzo et al. 2010) documents a decrease of VEGF mRNA expression concomitant with the induction of the uterine endothelial cells proliferation in adult rats exposed to BPA during the neonatal period.

Therefore, we investigated the ability of BPA to interfere with angiogenesis by means of an immortalized swine aortic endothelial cells line (AOC) (Carrillo et al. 2002). A first objective was the study of the direct effects of BPA on the development of new blood vessels, using a three-dimensional in vitro angiogenesis assay set up in our laboratory (Basini et al. 2014). Subsequently, potential changes in the synthesis of vascular endothelial growth factor (VEGF) and nitric oxide (NO), which represent key molecules in the regulation of angiogenic process, were examined.

\section{Material and Methods}

All reagents used were from Sigma Chemical Co Lt (St. Lovis, MO, USA), except those specifically mentioned. The immortalized porcine aortic endothelial cell line 
(AOC) used in the experiments was kindly provided by Prof. Jose Yélamos (Hospital Universitario Virgen de la Arrixaca, El Palmar, 30120 Murcia, Spain). The cells that were used at the $13^{\text {th }}$ passage, were grown in Medium 199 (containing Earle's salts and L-glutamine) supplemented with sodium bicarbonate $(2.2 \mathrm{mg} / \mathrm{mL}$ ), penicillin (100 IU / mL), streptomycin (100 mg / mL), amphotericin B $(2.5 \mathrm{mg} / \mathrm{mL})$ and $20 \% \mathrm{FBS}$ (Fetal Bovine Serum) (GIBCOTM, Invitrogen Corporation, UK) and incubated at $37^{\circ}$ $\mathrm{C}$ in a humidified atmosphere $\left(5 \% \mathrm{CO}_{2}\right)$. Bisphenol $\mathrm{A}$ was first dissolved in ethanol and then diluted in Medium 199 for the cell culture experiments. The same volume of ethanol was added to control wells.

\section{Fibrin gel angiogenesis assay}

The experimental model employed for the study of vascular development (Basini et al. 2014) was prepared using AOC grown on dextran beads coated with denatured collagen from porcine skin (citodex-3 microcarrier beads, MC), included in a gelatinous matrix of fibrin. The first stage of gel preparation involves the adhesion of cells to MC; to this aim, $1.25 \mathrm{mg}$ of $M C$ were incubated for 3 hours at $37^{\circ} \mathrm{C}$ with $1.5 \mathrm{~mL}$ of sterile PBS in order to achieve optimum hydration. After a first wash with sterile PBS and a second one with Medium 199, the MC were put into a flask containing $5.0 \mathrm{~mL}$ culture medium, and AOC $\left(5.0 \times 10^{5}\right)$ were added. The flask was then incubated overnight at $37^{\circ} \mathrm{C}$, in order to allow cell adhesion on the MC surface. Then, fibrin gels were prepared in 12 well plates, adding to each well, in the following order: $873 \mu \mathrm{L}$ of a fibrinogen solution $(1.0 \mathrm{mg} / \mathrm{mL} \mathrm{PBS}, \mathrm{pH} 7.6)$, $20 \mu \mathrm{L}$ of suspension of AOC coated MC, $128 \mu \mathrm{L}$ of thrombin $(5.0 \mathrm{U} / \mathrm{mL})$. Fibrin gel polymerization was obtained by incubation for 30 min at $37^{\circ} \mathrm{C}$, followed by a 1 hour balancing step with $2 \mathrm{~mL}$ of Medium 199. Thereafter, the medium was removed with an insulin syringe and replaced by Medium $199+20 \%$ FBS, containing BPA (0.1, 1 and $10 \mu \mathrm{M}$ ) (Grasselli et al. 2010) After 48 hours, media and treatments were renewed and the plates were incubated for additional $48 \mathrm{~h}$. Endothelial buds proliferation starting from $M C$ was quantified through the software for image processing, Scion Image Beta 4:02 (Scion Corporation, MA, USA, http://rsb.info.nih.gov/nih-image). After 48 and 96 hours of incubation five 
120 photographic images of each gel were acquired, each containing two or three $121 \mathrm{MC}$; images were then converted to grayscale, reduced by $50 \%$ (Paintbrush 122 Software, MS Office) and saved as 24-bit Bitmap, compatible with the program 123 Scion. The measurements in pixels were made by drawing the perimeter of the 124 area occupied by the AOC. The validity of this method for the quantification of 125 AOC proliferation was confirmed by evaluating the correlation between the area 126 covered by the AOC in fibrin gel and the number of cells actually present in the 127 same area (Basini et al. 2008).

\section{VEGF production}

The cells were seeded in 96-well plates at a density of $2.0 \times 10^{5}$ cells/ $200 \mu \mathrm{L}$ M199 $+20 \%$ FBS and treated for 48 hours with BPA at the indicated concentrations. The levels of VEGF in the culture media were quantified using an ELISA kit (Quantikine, R \& D Systems, Minneapolis, MI, USA) developed for human VEGF but validated also for the pig (Basini et al. 2000). Standard curve with concentration values between 0.039 and $2.0 \mathrm{ng} / \mathrm{mL}$ was used and the resulting colorimetric reaction was read at a wavelength of $450 \mathrm{~nm}$ with the spectrophotometer Multilabel Counter Victor3 (Perkin Elmer, Boston MA, USA). The sensitivity of the assay is 8.79 $\mathrm{pg} / \mathrm{mL}$ while the coefficients of variation within and between assay results are always less than $7 \%$.

\section{NO production}

142 The cells were seeded in 96-well plates at a concentration of $2.0 \times 10^{5}$ cells / 200 $\mu \mathrm{L}$ M199 + 20\% FBS and treated for 48 hours with BPA at the indicated concentrations. At the end of the incubation, the supernatants were collected and subjected to Griess test, in order to determine the content of nitric oxide (Dong and Yallampalli 1996). For this purpose, two solutions were prepared: 147 Reagent A (1\% sulfanilamide, 5\% phosphoric acid) and Reagent B $10.1 \% \mathrm{~N}-$ 148 [naphthyl] etilendiamine dihydrochloride). A standard curve of sodium nitrite, 
149 between $0.39 \mu \mathrm{M}$ and $25 \mu \mathrm{M}$, was set up in Medium 199. The assay was 150 performed in 96-well plates, adding $100 \mu \mathrm{L}$ of sample or $100 \mu \mathrm{L}$ of each point of the 151 curve and $50 \mu \mathrm{L}$ of solution A plus $50 \mu \mathrm{L}$ of solution B. The colorimetric reaction was 152 measured after 10 minutes at a wavelength of $540 \mathrm{~nm}$ with Multilabel Counter 153 Victor 3.

\section{Statistical Analysis}

Each experiment was repeated at least five times with six replicates for each treatment. The data are presented as mean \pm SEM (standard error of mean).

158 In all experiments, statistical differences were calculated by ANOVA using the software Statgraphics (STC Inc., Rockville, MD, USA).

When a significant difference $(p<0.05)$ was found, means were submitted to the Scheffé $F$ test for multiple comparisons.

\section{Results}

\section{Fibrin gel angiogenesis assay}

In our model, only the treatment with $10 \mu \mathrm{M}$ BPA displayed a detectable effect on AOC proliferation: actually, at this BPA concentration the area occupied by the AOC both after $48 \mathrm{~h}$ (Fig. 1 A and B) and $96 \mathrm{~h}$ of incubation (Fig. 2 A and B) were significantly ( $p<0.05$ ) increased. No significant differences were observed between the two different incubation times.

After $48 \mathrm{~h}$ and $96 \mathrm{~h}$ incubation, neither 0.1 nor $10 \mu \mathrm{M}$ BPA resulted effective in modifying AOC proliferative activity.

\section{VEGF production}


174 In AOC cell cultures incubated with different BPA concentrations for $48 \mathrm{~h}, \mathrm{a}$ 175 significant $(p<0.05)$ increase of VEGF production was observed in the presence of 176 BPA $10.0 \mu \mathrm{M}$, while neither 0.1 nor $1 \mu \mathrm{M}$ resulted effective in modulating VEGF levels 177 as compared to controls (Fig. 3) .

\section{NO production}

None of the concentrations of BPA tested displayed any effect on NO production by cultured AOC cells (Fig. 4).

\section{Discussion}

Previous studies have shown that BPA can interfere with the angiogenic process (Bredhult et al. 2007) in human endometrial endothelial cells, even if the mechanisms underlying this action have not been completely understood yet. This study, instead, documents that BPA directly stimulates the process of vascular growth probably enhancing VEGF production in endothelial cells only at the highest tested concentration of $10 \mu \mathrm{M}$, in agreement with previous findings (Long et al. 2001; Buteau-Lozano et al. 2008; Helmestam et al. 2014). In contrast, Bosquiazzo et al. (2010) showed a decrease of both VEGF mRNA expression and endothelial cells proliferation in adult rats exposed to BPA during the neonatal period.

Our data also document that BPA does not modulate NO production by endothelial cells, in contrast to what has been highlighted by Noguchi et al. (2002). The reasons for these opposing effects deserve to be further investigated.

Unfortunately, to date a systemic and integrated understanding of BPA disruptive actions is lacking. The evaluation of global consequences of BPA exposures, resulting from its use in the production of polycarbonates and epoxy resins for food and beverages containers and several other goods for human consumption (NTPCERHR 2008), appears still difficult due to an incomplete understanding of the 
202 cell/tissue specific actions and effects. It has been shown that BPA is constantly released in the environment (Oehlmann et al. 2008), and its presence has been detected in many biological fluids and tissues in humans and animals (Olea et al. 1996; Ikezuki et al. 2002; Schonfelder et al. 2002; Calafat et al. 2005; Fernandez et al. 2007; Kuruto-Niwa R et al. 2007). Most of the studies have been focused on the effects of low levels of BPA exposure deriving from a single source, while only a few have evaluated total BPA exposure from multiple potential sources, namely drinking water, dust and air (Vandenberg et al. 2007). Restrictions in the use of BPA in several countries induced its substitution by alternative bisphenols (BPXs), such as bisphenol S [BPS; 4,40-sulfonyldiphenol], bisphenol B [BPB; 2,20-bis(4hydroxyphenyl)butane], bisphenol F [BPF; 4,40-dihydroxydiphenylmethane], and bisphenol AF [BPAF; 4,40-(hexa-fivoroisopropylidene)diphenol] (FDA 2012). BPArelated compounds or bisphenols (BPXs) consist of two phenol groups bound through a carbon bridge or other chemical structures. Since BPXs are structurally similar to BPA, it is expected that they may have the same toxicological effects on the biological system (Usman and Ahmad 2016; Feng et al. 2016). In addition, potential transformation of bisphenol analogues under natural environmental conditions (mainly oxidation and photodegradation), which can lead to substances that mimic BPA toxicity, is stil uncompletely known thus requiring attention and future research efforts (Chen et al. 2016).

Our results raise concern about possible adverse effects following exposure to BPA. The concentrations tested in the present work are in accordance to those reported in scientific literature $\left(\begin{array}{lllll}10^{-13} & -10 & -4 & M\end{array}\right)$ for the investigations of its biological effects in different cell models, from different animal species and humans (reviewed in Wetherhill et al. 2007). In fact, in present study we found 10 $\mu \mathrm{M}\left(10^{-5} \mathrm{M}\right)$ as most effective concentration.

In general, extrapolation of the experimental results is limited by uncertainties on the relevance of experimental BPA doses adopted in the in-vitro investigations in comparison to the concentration levels that can be found in the environment, or the potential administration routes for the different organisms. 
232 In the past, a daily dose of $50 \mu \mathrm{g} / \mathrm{kg} /$ day was considered "safe" for humans, but 233 recent findings suggest that the real levels of human exposure to BPA exceed this 234 daily dose. On the basis of new investigations European Food Safety Authority 235 (EFSA) indicates that the up-to-date tolerable daily intake (TDI) must be lowered 236 from 50 to $4 \mathrm{\mu g} / \mathrm{kg} /$ day. BPA exposure through daily meal was considered an important part of the total body burden. Most of the BPA leaks from epoxy-coated canned foods or polycarbonate baby bottles. In addition to food or drink ingestion, other exposure pathways of environmental BPA should not be neglected. In general, inhalation was considered minor in total exposure, due in part that airborne BPA was relatively low compared to that of food intake. On the other hand, skin absorption of BPA is likely to be an important route because BPAcontaining thermal paper is often used in stores. Biedermann et al. (2010) indicated that following handling thermal printing paper for $5 \mathrm{sec}$, nearly $1 \mu \mathrm{g}$ of BPA $(0.2-6 \mu \mathrm{g})$ could migrate into the forefinger and the middle finger if skin was rather dry, whereas 10-fold of BPA transfer is measured if skin is wet or greasy. Recently, investigations of skin absorption and metabolic cytotoxicity mechanisms of BPA have been incorporated in risk assessment protocols (EFSA 2015).

Biomonitoring of BPA in various human tissues and fluids was reviewed by Asimakopoulos et al (2012). Urine traditionally represents the referred matrix to evaluate, in single individuals, both BPA exposure and elimination. Urine, in fact, contains a BPA byproduct that can be easily determined and quantitated. However, due to the short half-life of BPA in human tissues (6 h), the observed levels in urine of its byproduct can only reflect recent exposure to BPA, thus limiting its utility as a biomarker for low dose chronical administration. Bisphenol $A$ is highly glucuronidated also in the liver and is primarily excreted into the bile. Unconjugated (bioactive) BPA found in the blood and in the urine, indicates on one side an acute exposure to high levels of the compound, and on the other the failure of the conjugation process to glucuronic acid that brings detoxification. Being lipophilic, BPA can also contaminate adipose tissue (Bertoli et al. 2015).

Among the diseases characterized by excessive angiogenesis, Zhu and colleagues (2009) suggested that BPA might play a role in tumor progression. In the absence 
263 of vascularization, in fact, the tumors cannot exceed the size of 1 or $2 \mathrm{~mm}$ since 264 this represents the maximum distance through which oxygen and nutrient media freely diffuse from the vessels. Actually, tumor neovascularization provides oxygen and nutrients and also represents an essential element for the formation of metastases. Angiogenesis thus constitutes an event closely related to the state of malignancy (Pluda 1997). Among the angiogenic factors produced by the tumor cells or by inflammatory cells that infiltrate the tumor, VEGF plays a primary role (Ferrara and Davis-Smyth 1997). Zhu and co-workers (2009) have shown that BPA increases neuroblastoma mass volume and weight by augmenting microvessel density and VEGF synthesis. This study has been realized both in vivo, testing the concentration of $200 \mathrm{mg} / \mathrm{Kg}$, and in vitro at the concentration of $2.0 \mu \mathrm{g} / \mathrm{mL}$. The experimental data reported here suggest that these effects are likely due to a stimulatory effect on the angiogenic process by means of an ERs-dependent pathway. Interestingly, in addition to the effects attributable to a stimulation of neovascularization, this substance appears directly involved in tumor formation: BPA was shown to promote prostate cancer growth in mice (Wetherill et al. 2006), to increase the risk of mammary tumor development in rats (Durando et al. 2007) and to stimulate human seminoma cell proliferation (Bouskine et al. 2009). The role of angiogenesis is not limited to neoplastic progression since this process is involved in the genesis of many diseases, such as ovarian disfunctions, endometriosis, rheumatoid arthritis and diabetic retinopathy. In addition, it is now clear that the growth, development and regression of blood vessels are key features of reproduction. Physiological angiogenesis is an accurately regulated process in the female reproductive system during both non-pregnant estrous/menstrual cycle and implantation of embryos during pregnancy. Several experimental models have demonstrated that ovarian functions is critically dependent on angiogenesis for follicular development, ovulation and corpus luteum function. In particular, the development and regression of ovarian follicles and corpora lutea, which represent the functional units of the ovary, involve recurring and self limited angiogenesis (Ramakrishnan et al. 2005). Therefore, BPA exposure could be assumed as a risk factor not only for the onset of several pathological processes but also for the physiological events of the female reproductive cycle. Ptak and 
295 Gregoraszczuk (2015) recently demonstrated that BPA increased VEGF-R2 296 expression in ovarian cells thus suggesting a possible enhancement of pro-

297

298

299

300

301

302

303

304

305

306

307

308

309

310

311

312

313

314

315 angiogenic activity. Further studies are necessary in order to confirm and better define the effects of BPA on the angiogenic process, and also to investigate its mechanisms of action.

\section{Conclusions}

There is evidence that humans and animals are exposed to BPA continuously, mainly through skin contact and food ingestion. As a consequence BPA and its derivatives has been detected in human and animals fluids and tissues. The present data show that BPA (10 $\mu \mathrm{M})$ stimulates vascular growth enhancing VEGF production in endothelial cells. This effect should be considered negative, since angiogenesis is involved in several pathologies, such as cancer growth.

\section{Acknowledgments}

This research was supported by grant of the Università degli Studi di Parma (FIL).

\section{References}

Alizadeh, M., Ota, F., Hosoi, K., Kato, M., Sakai, T., and Satter, M.A. 2006. Altered allergic cytokine and antibody response in mice treated with Bisphenol A. J. Med. Invest. 53: 70-80.

Asimakopoulos, A.G., Thomaidis, N.S., and Koupparis, M.A. 2012. Recent trends in biomonitoring of bisphenol A, 4-t-octylphenol, and 4-nonylphenol. Toxicol. Lett. 210: 141-154.

Barboni, B., Turriani, M., Galeati, G., Spinaci, M., Bacci, M.L., Forni, M., and Mattioli, M. 2000. Vascular endothelial growth factor production in growing pig antral follicles. Biol. Reprod. 63: 858-864. 
Basini, G., Bussolati, S., Santini, S.E., Bianchi, F., Careri, M., Mangia, A., Musci, M., and Grasselli, F. 2008. Hydroxyestrogens Inhibit Angiogenesis in Swine Ovarian Follicles. J. Endocrinol. 199: 127-135.

323

Basini, G., Spatafora, C., Tringali, C., Bussolati, S., and Grasselli, F. 2014. Effects of a ferulate-derived dihydrobenzofuran neolignan on angiogenesis, steroidogenesis, and redox status in a swine cell model. J. Biomol. Screen. 19: 1282-1289.

Bertoli, S., Leone, A., and Battezzati, A. 2015. Human Bisphenol A Exposure and the "Diabesity Phenotype". Dose Response 13: 1559325815599173.

Biedermann, S., Tschudin, P., and Grob, K. 2010. Transfer of bisphenol A from thermal printer paper to the skin. Anal. Bioanal. Chem. 398: 571-576

Bosquiazzo, V.L., Varayoud, J., Muñoz-de-Toro, M., Luque, E.H., and Ramos, J.G. 2010. Effects of Neonatal Exposure to Bisphenol A on Steroid Regulation of Vascular Endothelial Growth Factor Expression and Endothelial Cell Proliferation in the Adult Rat Uterus. Biol. Reprod. 82: 86-95.

Bouskine, A., Nebout, M., Brücker-Davis, F., Benahmed, M., and Fenichel, P. 2009. Low dose of bisphenol A promote human seminoma cell proliferation by activating PKA and PKG via a membrane G-protein-coupled estrogen receptor. Environ. Health Perspect. 117: 1053-1058.

Bredhult, C., Bäcklin, B.M., and Olovsson. M. 2007. Effects of some endocrine disruptors on the proliferation and viability of human endometrial endothelial cells in vitro. Reprod. Toxicol. 23: 550-559.

Buteau-Lozano, H., Velasco, G., Cristofari, M., Balaguer, P., and PerrotApplanat, M. 2008. Xenoestrogens modulate vascular endothelial growth factor secretion in breast cancer cells trough an estrogen receptor-dependent mechanism. J. Endocrinol. 196: 399-412. 
Calafat, A.M., Kuklenyik, Z., Reidy, J.A., Caudill, S.P., Ekong, J., and Needham, J.L. 2005. Urinary concentrations of bisphenol A and 4-nonylphenol in a human reference population. Environ. Health Perspect. 113: 391-395

Carrillo, S., Chamorro, M., Rodriguez-Gago, B., Alvarez, B., Molina, M.J., Rodríguez-Barbosa, J.I., Sánchez, A., Ramírez, P., Muñoz, A., Domínguez, J., Parrilla, P., and Yélamos, J. 2002. Isolation and characterization of immortalized porcine aortic endothelial cell lines. Vet. Immunol. Immunopathol. 89: 91-98.

Caserta, D., Di Segni, N., Mallozzi, M., Giovanale, V., Mantovani, A., Marci, R., and Moscarini, M. 2014. Bisphenol A and the female reproductive tract: an overview of recent laboratory evidence and epidemiological studies. Reprod. Biol. Endocrinol. 12: 37.

Chen D., Kannan K., Tan H., Zheng Z., Feng YL, Wu Y, and Widelka M. 2016. Bisphenol A analogues other than BPA: environmental occurrence, human exposure, and Toxicity- a review. Environ. Sci. Technol. 50: 5438-5453.

Dong, Y.L., and Yallampalli, C. 1996. Interaction between nitric oxide and prostaglandin E2 pathways in pregnant rat uteri. Am. J. Physiol. 270: 471-476.

Durando, M., Kass, L., Piva, J., Sonnenschein, C., Soto, A.M., Luque, E.H., and Muñoz-de-Toro, M. 2007. Prenatal Bisphenol A Exposure Induces Preneoplastic Lesions in the Mammary Gland in Wistar Rats. Env. Health Perspect. 115: 80-86.

European Food Safety Authority (EFSA) Factsheets: EFSA explains the safety of bisphenol A. Available at: http://www.efsa.europa.eu/sites/default/files/corporate_publications/files/facts heetbpa150121.pdf. Accessed May 2016

FDA., Food and Drug Administration. 2012. Indirect Food Additives, vol. 77, Federal Register (2012) http://www.gpo.gov/fdsys/pkg/FR-2012-07-17/pdf/201217366.pdf 
372 Feng, Y., Jiao, Z., Shi, J., Li, M., Guo, Q., and Shao, B. 2016. Effects of bisphenol analogues on steroidogenic gene expression and hormone synthesis in H295R cells. Chemosphere, 147:9-19.

Fernandez, M.F., Arrebola, J.P., Taoufiki, J., Navalon, A., Ballesteros, O., Pulgar, R., Vilchez, J.L., and Olea, N. 2007. Bisphenol-A and chlorinated derivatives in adipose tissue of women. Reprod. Toxicol. 24: 259-264.

Ferrara, N., and Davis-Smyth, T. 1997. The biology of vascular endothelial growth factor. Endocr. Rev. 18: 4-25.

Grasselli, F., Baratta, L., Baioni, L., Bussolati, S., Ramoni, R., Grolli, S., and Basini, G. 2010. Bisphenol A disrupts granulosa cell function. Domest. Anim. Endocrinol. 39: 34-39.

Helmestam, M., Davey, E., Stavreus-Evers, A., and Olovsson, M. 2014. Bisphenol A affects human endometrial endothelial cell angiogenic activity in vitro. Reprod. Toxicol. 46: 69-76.

Ho, S.M., Tang, W.Y., Belmonte de Frausto, J., and Prins, G.S. 2006. Developmental exposure to estradiol and bisphenol A increases susceptibility to prostate carcinogenesis and epigenetically regulates phosphodiesterase type 4 variant 4. Cancer Res. 66: 5624-5632.

Howdeshell, K.L., Hotchkiss, A.K., Thayer, K.A., Vandenbergh, L.G., and vom Saal, F.S. 1999. Exposure to bisphenol A advances puberty. Nature, 401: 763-764.

Ikezuki, Y., Tsutsumi, O., Takai, Y., Kamei, Y., and Taketani, Y. 2002. Determination of Bisphenol A concentrations in human biological fluids reveals significant early prenatal exposure. Hum. Reprod. 217: 2839-2841.

Kuruto-Niwa, R., Tateoka, Y., Usuki, Y., and Nozawa, R. 2007. Measurement of bisphenol A concentrations in human colostrums. Chemosphere 66: 1160-1164.

Long, X., Burke, K.A., Bigsby, R.M., and Nephew KP. 2001. Effects of Xenoestrogen Bisphenol A on Expression of Vascular Endothelial Growth Factor (VEGF) in the Rat. Exp. Biol. Med. 226: 477-483. 
Lyons, G. 2000. Bisphenol A. A known Endocrine Disruptors. A WWF European Toxics Programme Report.

Available at:

nttp:// www.wwf.org.uk/filelibrary/pdf/bpa.pdf

Markey, C.M., Coombs, M.A., Sonnenschein, C., and Soto, A.M. 2003. Mammalian development in a changing environment: exposure to endocrine 405 disruptors reveals the developmental plasticity of steroid-hormone target organs. Evol. Dev. 5: 67-75

407

408

409

410

411

412

413

414

415

416

417

418

419

Markey, C.M., Luque, E.H., Munoz De Toro, M., Sonnenschein, C., and Soto, A.M. 2001. In utero exposure to bisphenol A alters the development and tissue organization of the mouse mammary gland. Biol. Reprod. 65: 1215-1223.

Miyatake, M., Miyagawa, K., Mizuo, K., Narita, M., and Suzuki, T. 2006. Dynamic changes in dopaminergic neurotransmission induced by a low concentration of bisphenol-A in neurones and astrocytes. J. Neuroendocrinol. 18: 434-444.

Moriyama, K., Tagami, T., Akamizu, T., Usui, T., Saijo, M., Kanamoto, N., Hataya, Y., Shimatsu, A., Kuzuya, H., and Nakao, K. 2002. Thyroid hormone action is disrupted by bisphenol A as an antagonist. J. Clin. Endocrinol. Metab. 87: 51855190.

Noguchi, S., Nakatsuka, M., Asagiri, K., Habara, T., Takata, M., Konishi, H., and Kudo, T. 2002. Bisphenol A stimulates NO synthesis trough a non-genomic estrogen receptor-mediated mechanism in mouse endothelial cells. Toxicol. Lett. 135: 95-101.

NTP-CERHR. 2008. Monograph on the potential human reproductive and developmental effects of Bisphenol A. NIH Publication No.08-5994.

Oehlmann, J., Oetken, M., and Schulte-Oehlmann, U. 2008. A critical evaluation of the environmental risk assessment for plasticizers in the freshwater environment in Europe, with special emphasis on bisphenol $A$ and endocrine disruption. Environ. Res. 108: 140-149. 
Olea, N., Pulgar, R., Perez, P., Olea-Serrano, F., Rivas, A., Novillo-Fertrell, A., Pedraza, V., Soto, A.M., and Sonnenschein C. 1996. Estrogenicity of resin-based composites and sealants used in dentistry. Environ. Health Perspect. 104: 298305.

Pluda, J.M. 1997. Tumor-associated angiogenesis: mechanisms, clinical implications, and therapeutic strategies. Semin. Oncol. 24: 203-218.

Ramakrishnan, S., Subramanian, I.V., Yokoyama, Y., and Geller, M. 2005. Angiogenesis in normal and neoplastic ovaries. Angiogenesis. 8: 169-182.

Rubin, B.S., Lenkowski, J.R., Schaeberle, C.M., Vandenberg, L.N., Ronsheim, P.M., and Soto AM. 2006. Evidence of altered brain sexual differentiation in mice exposed perinatally to low, environmentally relevant levels of bisphenol A. Endocrinology. 147: 3681-3691.

Rubin, B.S., Murray M.K., Damassa, D.A., King, J.C., and Soto, A.M. 2001. Perinatal exposure to low doses of bisphenol A affects body weight, patterns of Estrous cyclicity, and plasma LH levels. Environ. Health Perspect. 109: 675-680.

Schonfelder, G., Wittfoht, W., Hopp, H., Talsness, C.E., Paul, M., and Chahoud I. 2002. Parent bisphenol A accumulation in human maternal-fetal-placental unit. Environ. Health Perspect. 110: A703-A707.

Usman A. and Ahmad M. 2016. From BPA to its analogues: is it a safe journey? Chemosphere 158: 131-142.

452

vom Saal, F.S., Cooke, P.S., Buchanan, D.L., Palanza, P., Thayer, K.A., Nagel, S.C., Parmigiani, S., and Welshons, W.V. 1998. A physiologically based approach to the study of bisphenol $A$ and other estrogenic chemicals on the size of reproductive organs, daily sperm production, and behavior. Toxicol. Ind. Health.14: 239-260.

Welshons, W.V., Nagel, S.C., and vom Saal, F.S. 2006. Large effects from small exposures.III.Endocrine mechanisms mediating effects of bisphenol $A$ at levels of human exposure. Endocrinology 147: S56-S69. 
455 Wetherill, Y.B., Akingbemi, B.T., Kanno, J., Mclachlan, J.A., Nadal, A., 456 Sonnenschein, C., Watson, C.S., Zoeller, R.T., and Belcher, S.M. 2007. In vitro 457 molecular mechanisms of bisphenol A action. Reprod. Toxicol. 24: 178-198.

458 Wetherill, Y.B., Hess-Wilson, J.K., Comstock, C.E., Shah, S.A., Buncher, C.R., 459 Sallans, L., Limbach, P.A., Schwemberger, S., Babcock, G.F., and Knudsen, K.E. 460 2006. Bisphenol A facilitates bypass of androgen ablation therapy in prostate 461 cancer. Mol. Cancer Ther. 5: 3181-3190.

462 Zhu, H., Xiao, X., Zheng, J., Zheng, S., Dong, K., and YU, Y. 2009. Growth463 promoting effect of bisphenol A on neuroblastoma in vitro and in vivo. J 464 Pediatr. Surg. 44: 672-680. 


\section{Figure captions}

Fig. 1. Effect of the treatment with bisphenol $\mathrm{A}(0.1,1$ or $10 \mu \mathrm{M})$ for $48 \mathrm{~h}$ on angiogenesis. (A): phase contrast micrographs showing AOC growth in fibrin gel matrix. (B): area covered by AOC. Different letters indicate a significant difference $(p<0.05)$ among treatments as calculated by ANOVA and Scheffè' $F$ test.

Fig. 2. Effect of the treatment with bisphenol $A(0.1,1$ or $10 \mu \mathrm{M})$ for $96 \mathrm{~h}$ on angiogenesis. (A): phase contrast micrographs showing $A O C$ growth in fibrin gel matrix. (B): area covered by AOC. Different letters indicate a significant difference $(p<0.05)$ among treatments as calculated by ANOVA and Scheffè' $F$ test.

Fig. 3. Effect of the treatment with bisphenol $A(0.1,1$ or $10 \mu M)$ on VEGF production by AOC. Different letters indicate a significant difference $(p<0.05)$ among treatments as calculated by ANOVA and Scheffè' $F$ test.

Fig. 4. Effect of the treatment with bisphenol $A(0.1,1$ or $10 \mu \mathrm{M})$ on NO production by AOC. 


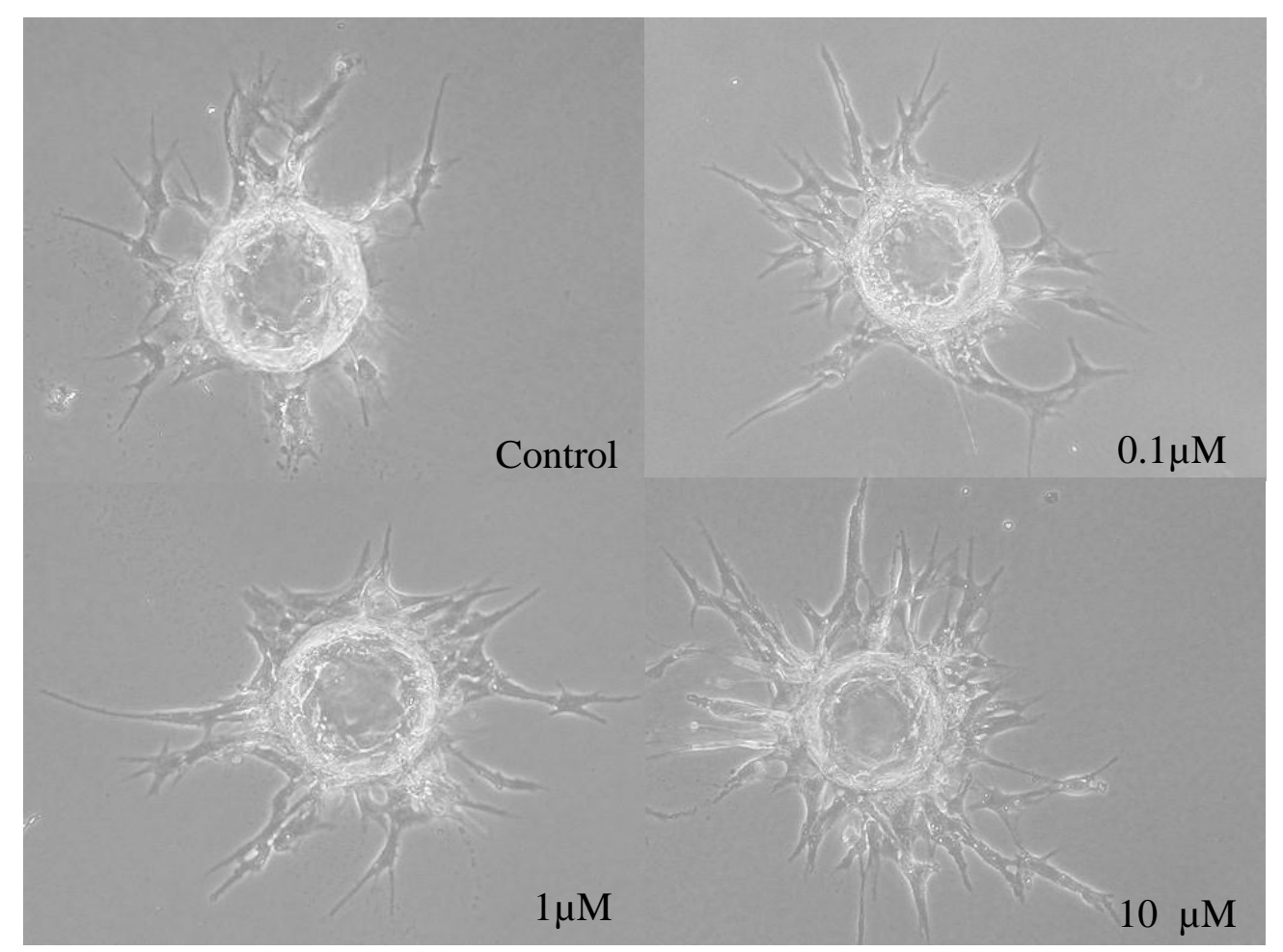

A

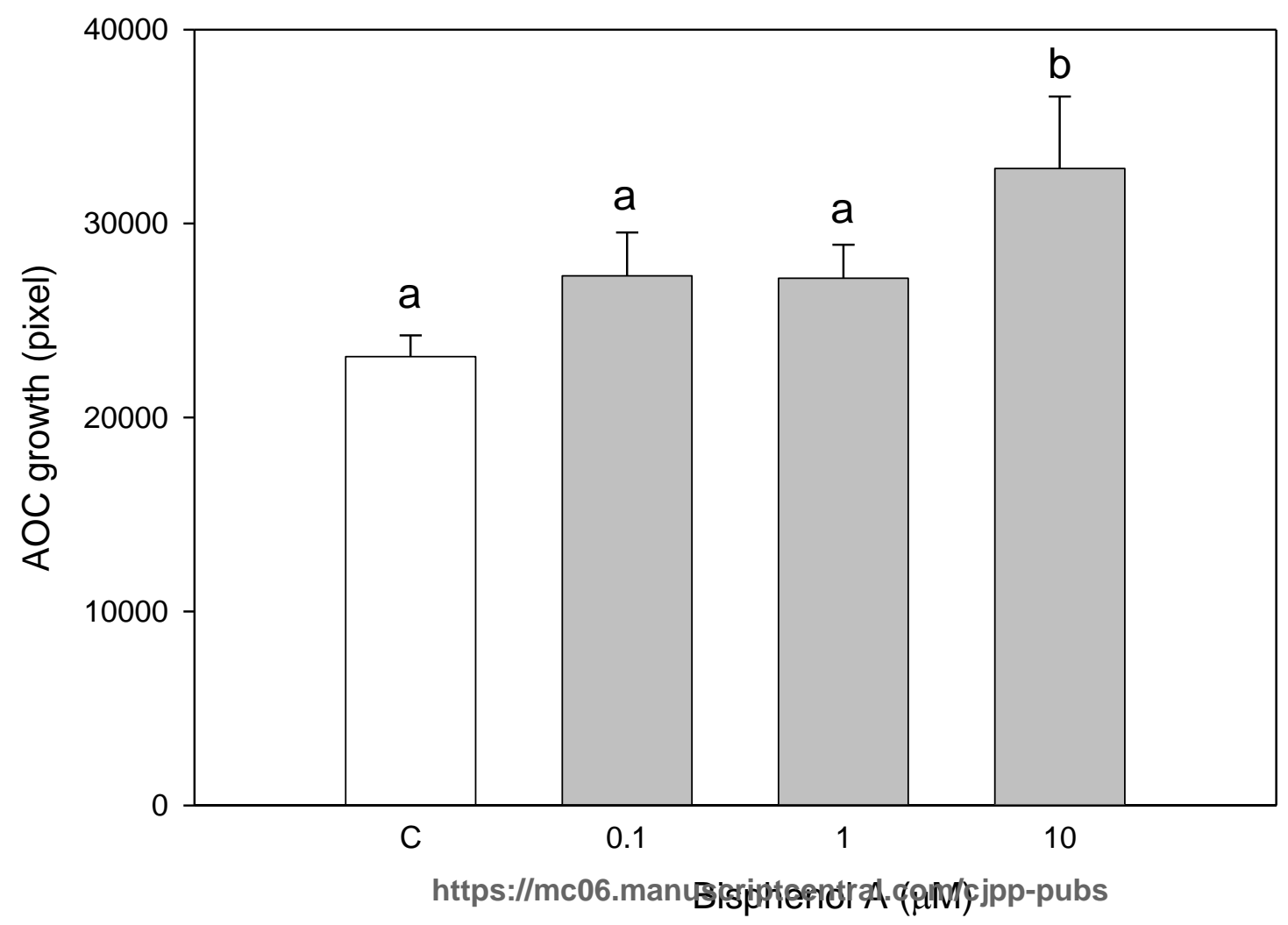

B 


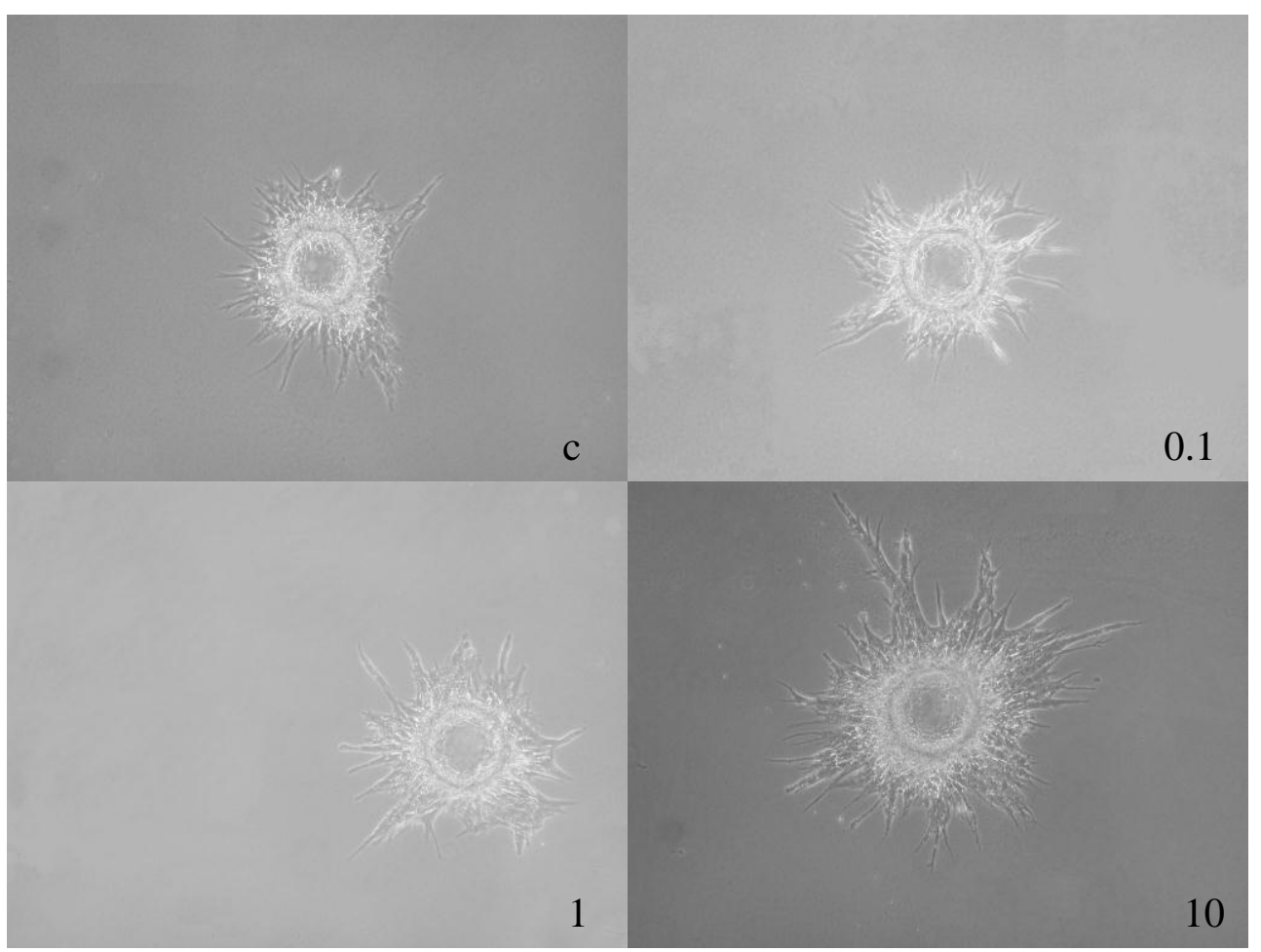

A

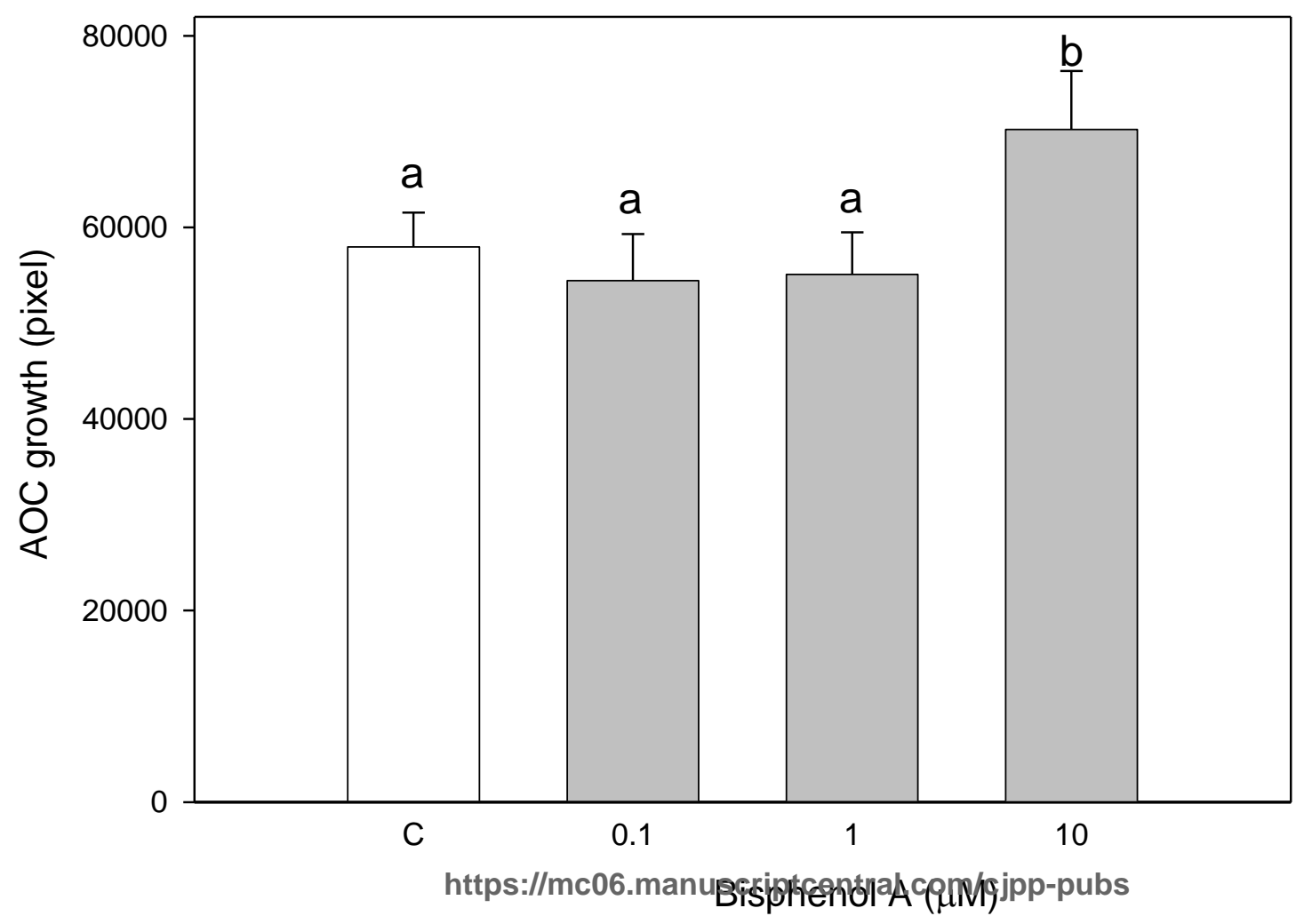

B 


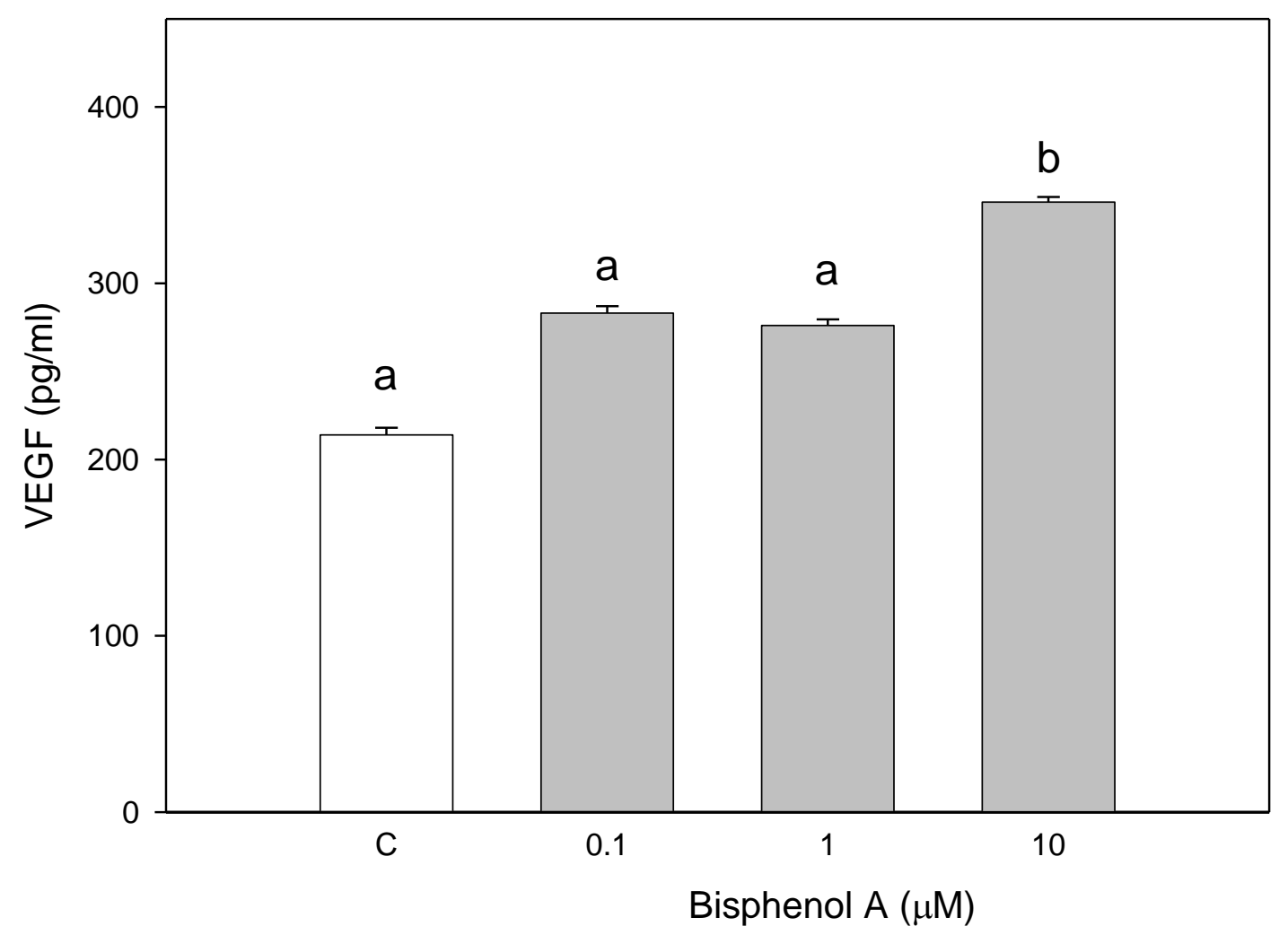

https://mc06.manuscriptcentral.com/cjpp-pubs 


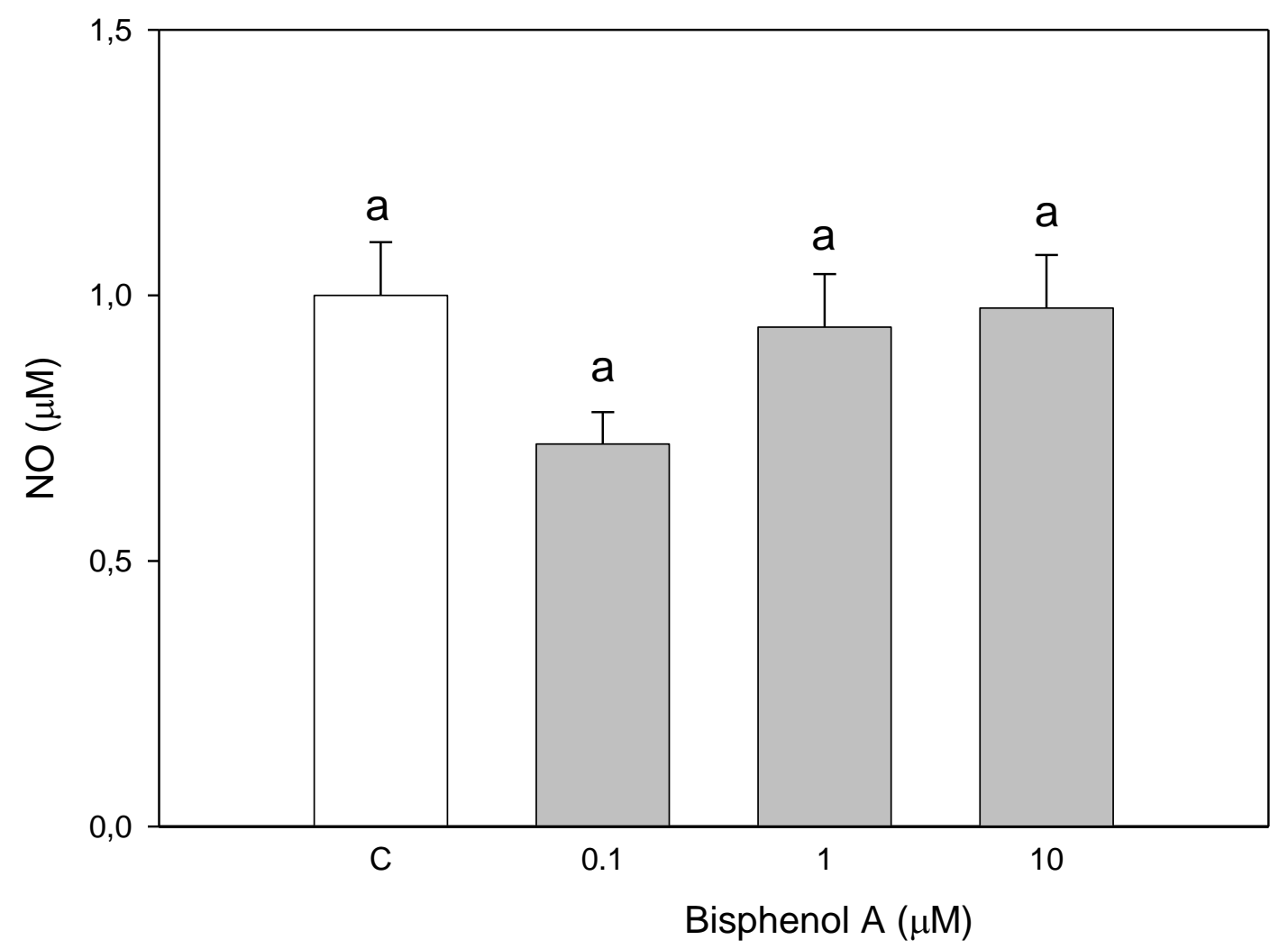

https://mc06.manuscriptcentral.com/cjpp-pubs 